Journal of Sustainable and Manufacturing in Transportation

\title{
Finite Element Analysis of Piston for Structural Assessments
}

\author{
Muhammad Hilman Karem $^{1}$, Al Emran Ismail ${ }^{1 *}$ \\ ${ }^{1}$ Faculty of Mechanical and Manufacturing Engineering, \\ Universiti Tun Hussein Onn Malaysia (UTHM), Parit Raja, 86400, MALAYSIA \\ *Corresponding Author
}

DOI: https://doi.org/10.30880/jsmt.2021.01.01.002

Received 24 August 2021; Accepted 11 October 2021; Available online 15 December 2021

\begin{abstract}
This paper presents the assessment of different piston head geometry made of aluminum and magnesium alloy. ANSYS finite element analysis is used to analyze the piston under static and transient conditions. Round and flat piston head is constructed using SOLIDWORK software and the exported to ANSYS WORKBENCH. According to static analysis, it is found that flat head piston produced higher stress compared with round head piston. Similar trend is observed when transient analysis is conducted where round piston head capable to produce almost stress consistency with respect to time.
\end{abstract}

Keywords: Finite Element Analysis (FEA), piston, structural performances, ANSYS

\section{Introduction}

Among other related mechanisms, a piston is a part of reciprocating motors, reciprocating pumps, gas compressors, hydraulic cylinders and pneumatic cylinders. It is the moving part that a cylinder contains and is made of piston rings that are gas tight. Along the development of automobile technology, the reliability, efficiency, durability, low exhaust gas and noise and operating performance of automobile engines is wished to be carried to a higher level. Piston is well known that almost all these properties of an internal combustion engine are closely associated with its mechanical behaviors (Wang, 2010). In order to improve its general property and efficiency, it is therefore necessary to disclose these mechanical characteristics of an engine and it is much more important in the piston system.

The main part of a pressure balance is its piston-cylinder unit using for measuring pressure in metrology science (Yagmur, 2008). At higher pressures, the elastic deformation of both the piston and cylinder induces a change in the effective area of the unit. The elastic distortions are related to the pressure applied, the unit's material properties and the pressure properties. The damage of one component often leads to the failure of entire engine, so the reliability of engine has become a focus of attention (Wang, 2017). The main role of the piston is to shape the combustion chamber with the cylinder liner and the cylinder head as an essential part of the engine, to withstand the explosion pressure when gas burns, and to operate outwardly through the connecting rod and crankshaft. In the one hand, the piston output has a direct effect on the engine performance, on the other hand, the piston is subjected to high thermal and mechanical loads and the cyclical variation of the engine performance.

Damage identification is not always a straightforward task. In certain situations, the damage in the images can be difficult to spot, or it may not be readily evident that any damage is present. In the field of engineering, the outcome of failure must be accurate. Finite Element Analysis would then be able to evaluate the design generated when all the parameters are known, which then display the best outcome. These include the piston engine can cause damage to both car and an engine. Next, the failure of the piston must be studied in order to avoid further damage to human being. In this paper, ANSYS finite element analysis software is used to assess the structural performances of piston under pressure. 


\section{Materials and Method}

The materials and methods section, otherwise known as methodology, describes all the necessary information that is required to obtain the results of the study. Product simulation is now also carried out by engineering groups using niche simulation software from various suppliers to simulate different design attributes. The use of different software products from suppliers causes inefficiencies and raises costs. It develops and markets simulation software for product design, testing and operation for Multiphysics engineering and provides its products and services to clients worldwide. Ansys develops and markets tools for the simulation of engineering for use throughout the product life cycle. Ansys Mechanical finite element analysis software is used to simulate structural, electronic, or system part computer models for resilience, durability, elasticity, distribution of temperature, electromagnetism, fluid flow, and another attributes analysis. Ansys is used to assess how a product performs without constructing test products or performing crash tests for various requirements. Ansys software, for example, can simulate how after years of traffic a bridge would hold up, how to better process salmon in a cannery to minimize waste, or how to build a slide that uses less material without compromising security.

The sketch drawing can then be converted into a technical drawing using SolidWorks after the sketch drawing is completed. The drawing will start from the piston head and then follow by piston rod and cap. The final step of technical drawing is using the center piston head area as a reference and the measure from the reference point to the any section that has at the piston such as piston rod section, piston pin section and piston cap section. Then it is equivalent or not compared with the sketch drawing. Change any of the dimensions on the drawing of the piston head if the distance is not close. In the sketch drawing, the shape, angle, and distance were referred to. To complete the piston drawing, draw another part of the piston for assembly. Figure 1 shown the technical drawing assembly of two different type of piston which are round head piston and flat head piston from SolidWorks software.

In several engineering fields, the finite element approach is widely used. With the use of computer-based technique it breaks geometry into elements and links a series of equations to each and solves the equations simultaneously to evaluate the behavior of the entire system (Srivastav et al., 2015). There are several steps in FEA to run simulations such as design and modelling, specified boundary condition of material used, generation and result of meshing. In this simulation, the nonlinear study function was chosen in this simulation and was carried out by applying the force in one direction on the pin area at the ball pin ball joint to achieve the full value of stress, displacement and strain. The generation of meshing is the critical component before the FEA simulation is run. This form of meshing defines small features and curved geometries that can have a broad aspect ratio or failure of the mesh. The characteristics of the mesh for two different pistons based on Table 1 while Table 2 tabulates the mechanical properties of the materials used in this work.

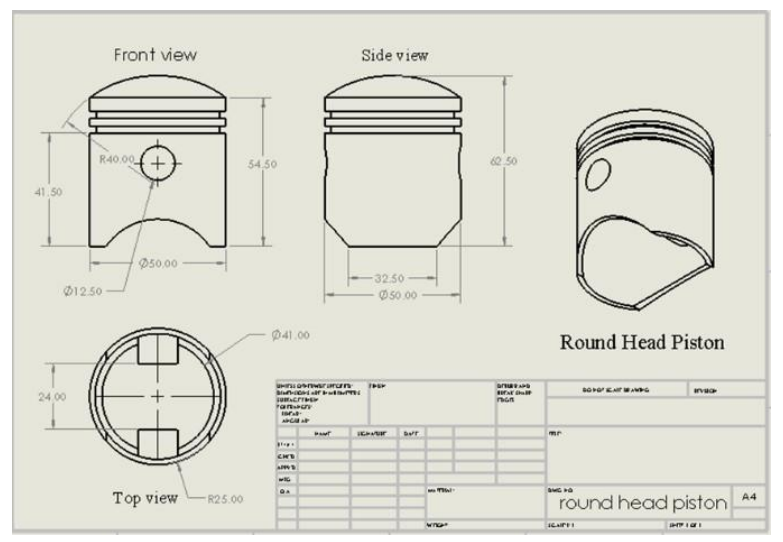

(a)

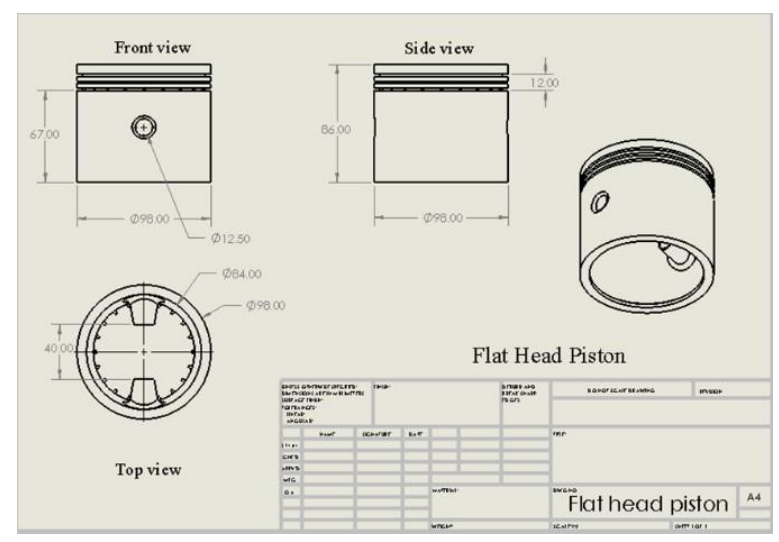

(b)

Fig. 1 - (a) Layout view for round head piston; (b) layout view for flat head piston

Table 1 - Meshing details

\begin{tabular}{llll}
\hline Model & Element size $(\mathrm{mm})$ & Node number & Element number \\
\hline Round head piston & 3.0 & 50405 & 25715 \\
Flat head piston & 3.0 & 122822 & 67961 \\
\hline
\end{tabular}


Table 2 - Structural properties of material

\begin{tabular}{ccc}
\hline Property & Aluminium alloy & Magnesium alloy \\
\hline Young modulus & 78000 & 45000 \\
Poisson ratio & 0.33 & 0.35 \\
Bulk modulus & 69608 & 50000 \\
Shear modulus & 26692 & 16667 \\
Yield strength & 280 & 193 \\
Ultimate strength & 310 & 255 \\
\hline
\end{tabular}

\section{Results and Discussions}

\subsection{Static Structural Analysis}

Static structural analysis is a crucial step in the design process. The response of the structure to applied external forces is determined using static analysis. Internal forces or moments and internal stresses are employed in the design process to determine the structure of the piston's response. The pressure was applied from top each of head piston with different geometry and material. The value of the pressure used was $15.4 \mathrm{MPa}$ at every top of head piston as in Figure 2. Details of stresses are tabulated in Table 3.

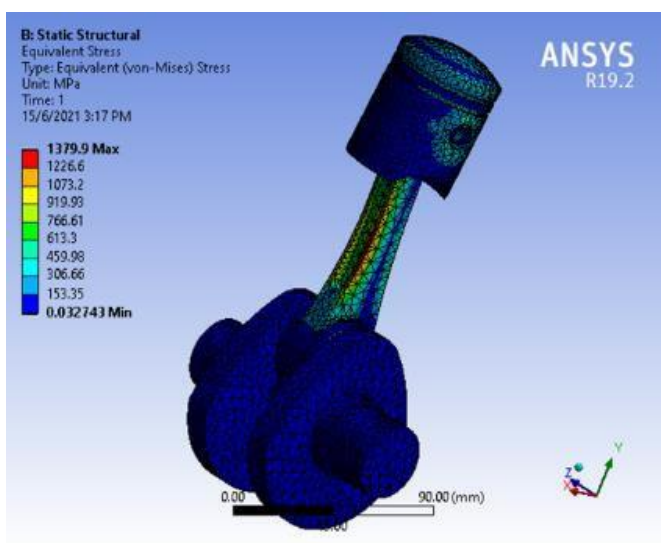

(a)

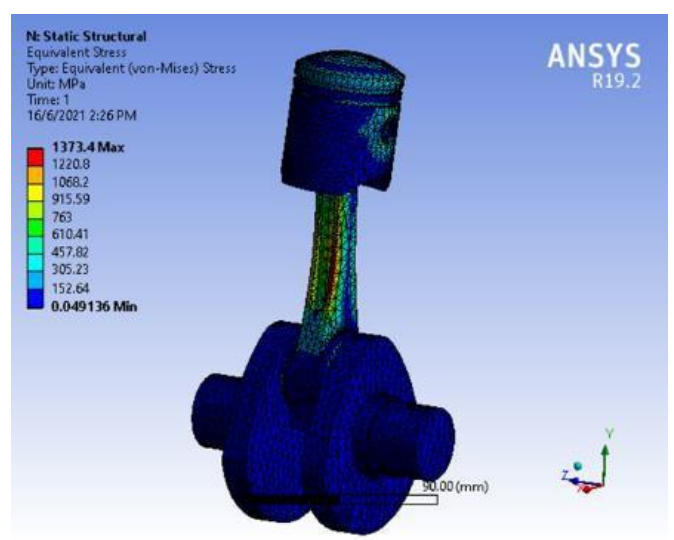

(c)

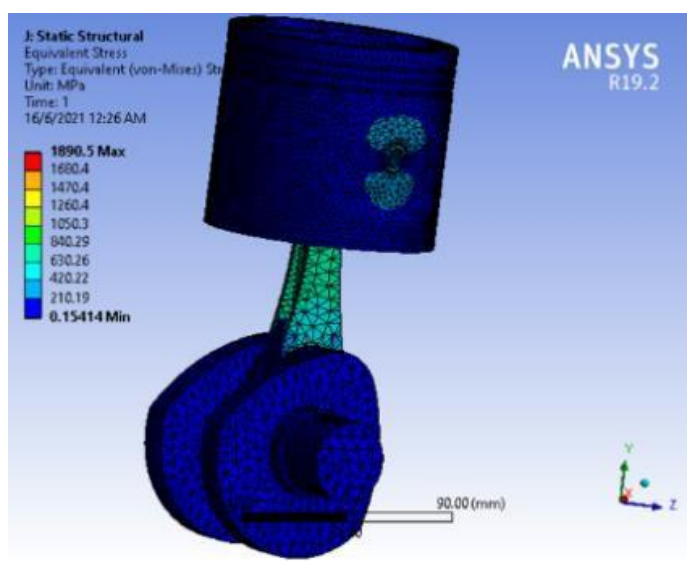

(b)

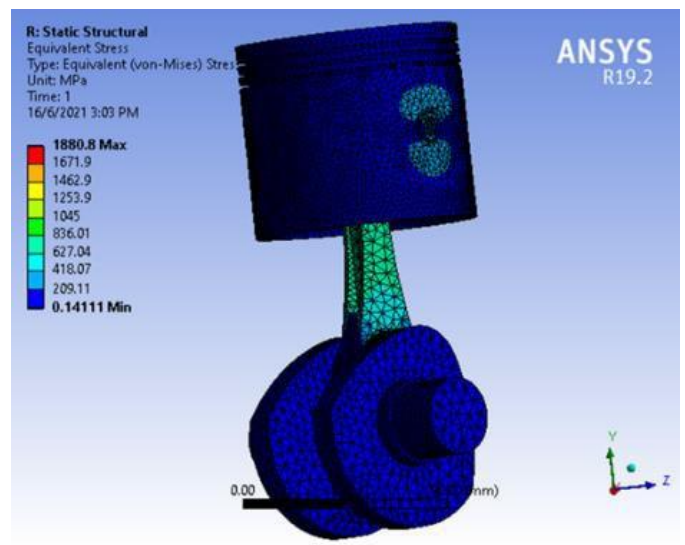

(d)

Fig. 2 - Equivalent stress result (a) Round head piston aluminium alloy; (b) Flat head pistonaluminium alloy (c) Round head piston magnesium alloy; (d) Flat head piston magnesium alloy 
Table 3 - Equivalent von-Mises stress results

\begin{tabular}{|c|c|c|c|}
\hline Name of pistons & Minimum (MPa) & Maximum (MPa) & Average $(\mathrm{MPa})$ \\
\hline Round head aluminiumalloy piston & 0.032743 & 1379.9 & 114.6 \\
\hline Flat head aluminium alloy piston & 0.15414 & 1890.5 & 123.04 \\
\hline Round head magnesiumalloy piston & 0.049136 & 1373.4 & 114.47 \\
\hline Flat head magnesium alloy piston & 0.14111 & 1880.8 & 122.84 \\
\hline
\end{tabular}

\subsection{Thermal Analysis}

The thermal equilibrium of a system in which the temperature remains constant over time is evaluated using steady-state thermal analysis. The temperature applied to each piston were $660{ }^{\circ} \mathrm{C}$ and applied on top head of pistons. Each test piston will produce a different value of temperature according to material and geometry of pistons. Radiation applied at the crankshaft and the value ambient temperature used were $22^{\circ} \mathrm{C}$ as in Figure 3 while Table 4 list the detail of maximum and minimum temperatures.

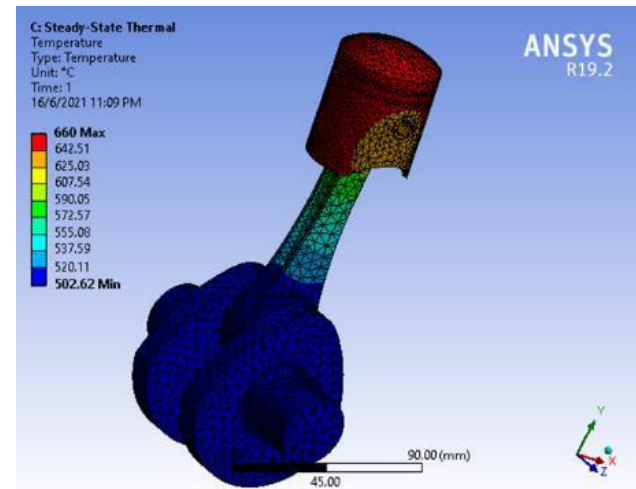

(a)

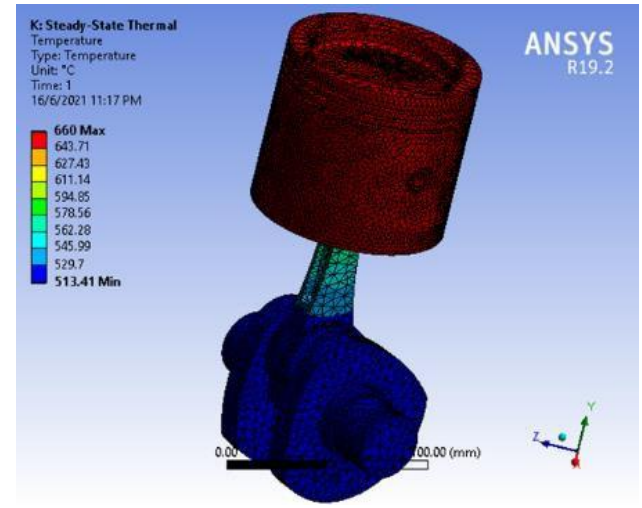

(c)

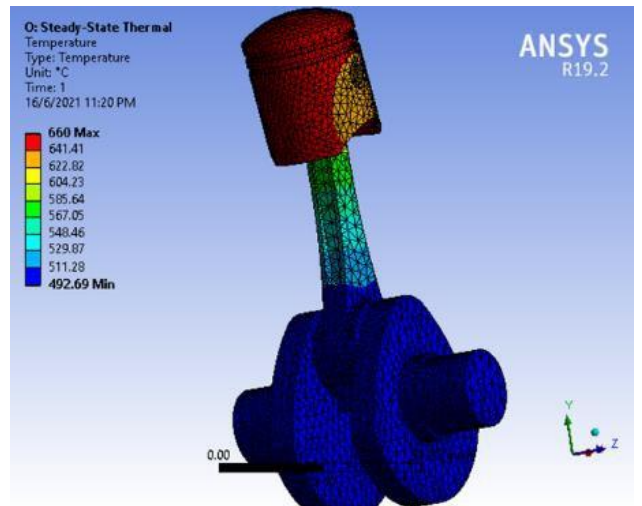

(b)

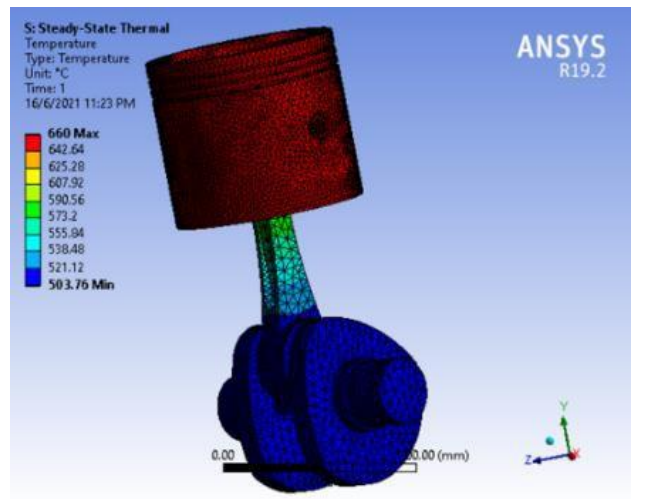

(d)

Fig. 3 - Thermal analysis results (a) Round head aluminium alloy piston; (b) Round head magnesiumalloy piston; (c) Flat head aluminium alloy piston; (d) Flat head magnesium alloy piston

Table 4 - Comparison of temperatures

\begin{tabular}{cccccc}
\hline No & Piston & Material & Minimum $\left({ }^{\circ} \mathrm{C}\right)$ & Maximum $\left({ }^{\circ} \mathrm{C}\right)$ & Average $\left({ }^{\circ} \mathrm{C}\right)$ \\
\hline \multirow{2}{*}{1} & \multirow{2}{*}{ Round headpiston } & Aluminium alloy & 502.62 & 660 & 565.47 \\
& & Magnesium alloy & 492.69 & 660 & 559.5 \\
\hline \multirow{2}{*}{2} & \multirow{2}{*}{ Flat head piston } & Aluminium alloy & 513.41 & 660 & 624.65 \\
& & Magnesium alloy & 503.76 & 660 & 622.32 \\
\hline
\end{tabular}




\subsection{Total Heat Flux}

Heat flux, also known as thermal flux or heat flux density, is a term used to describe the amount of heat that flows through a system. It is a vector quantity since it has both a direction and a magnitude. Figure below show the result of total heat flux on each piston. Figure 4 shows the distribution of heat flux across the pistons and Table 5 compares maximum, minimum, and average temperatures of the piston made of different materials.

\subsection{Transient Structural Analysis}

The process of calculating and assessing the effects of loads and internal forces on a structure or an object as a function of time is known as transient structural analysis. The piston was fabricated from aluminium alloy. Figure 6 shows the graph equivalent stress over time and transient structural analysis result from the piston. While maximum and minimum temperatures are tabulated in Table 7.

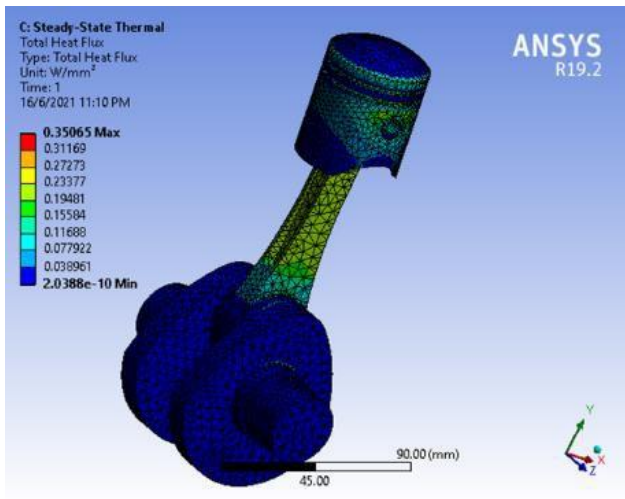

(a)

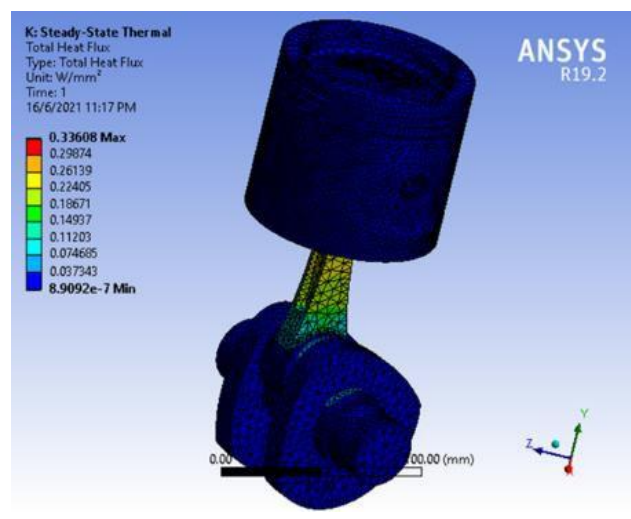

(c)

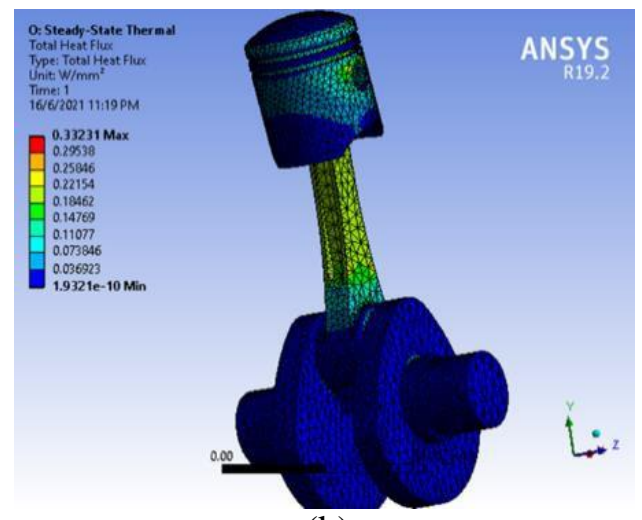

(b)

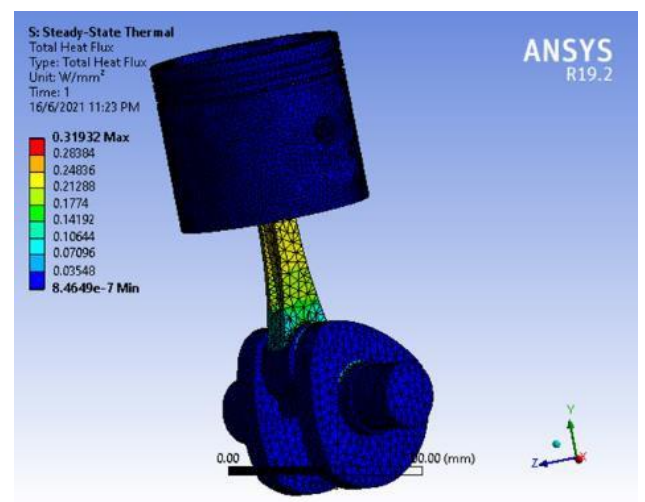

(d)

Fig. 4 - Total heat flux results (a) Round head aluminium alloy piston; (b) Round head magnesiumalloy piston; (c) Flat head aluminium alloy piston; (d) Flat head magnesium alloy piston

Table 5 - Comparison total heat flux

\begin{tabular}{cccccc}
\hline \multirow{2}{*}{ No } & \multirow{2}{*}{ Piston } & Material & Minimum $\left({ }^{\circ} \mathrm{C}\right)$ & Maximum $\left({ }^{\circ} \mathrm{C}\right)$ & Average $\left({ }^{\circ} \mathrm{C}\right)$ \\
\hline \multirow{2}{*}{1} & \multirow{2}{*}{ Round headpiston } & Aluminium & 0.0000000002033 & 0.35065 & 0.052484 \\
& \multirow{2}{*}{ Flat head piston } & Magnesium & 0.00000000019321 & 0.33231 & 0.049739 \\
\hline \multirow{2}{*}{2} & Aluminium & 0.00000089092 & 0.33608 & 0.022007 \\
& & Magnesium & 0.00000084649 & 0.31932 & 0.020909 \\
\hline
\end{tabular}




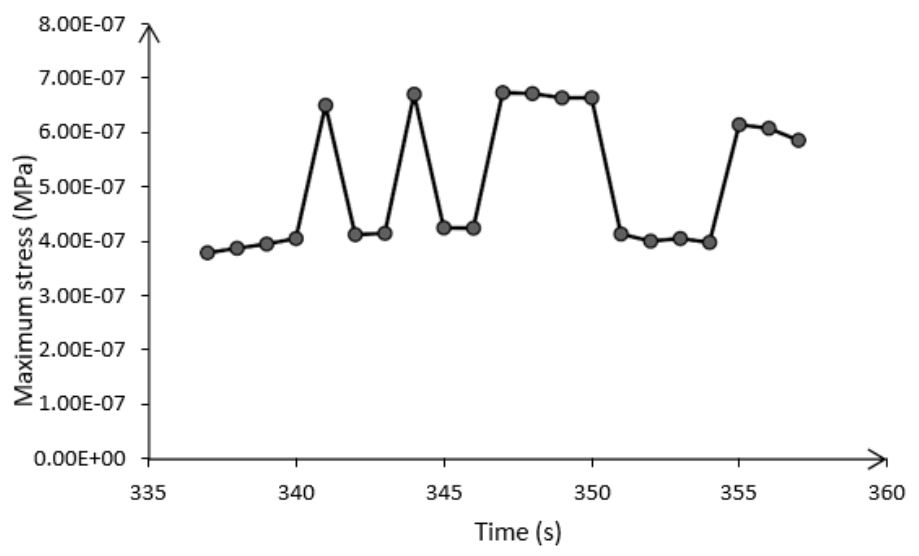

Fig. 5 - Equivalent von mises stress vs time

Table 6 - Maximum value over time aluminium alloy round head piston

\begin{tabular}{|c|c|c|}
\hline Object name & \multicolumn{2}{|c|}{$\operatorname{Minimum}(\mathrm{Pa})$} \\
\hline Equivalent stress & & \\
\hline & 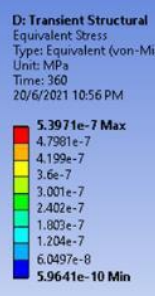 & $\begin{array}{r}\text { ANSYS } \\
\text { R19.2 }\end{array}$ \\
\hline
\end{tabular}

Fig. 6 - Transient structural analysis on aluminium alloy round head piston

Table 7 - Equivalent stress transient structural analysis of round head piston (aluminium alloy)

\begin{tabular}{ccccc}
\hline \multicolumn{2}{c}{ Object name } & Minimum $(\mathrm{Pa})$ & Maximum $(\mathrm{Pa})$ & Average $(\mathrm{Pa})$ \\
\hline Equivalent & von-Mises Stress & 0.00059641 & 0.53971 & 0.0078472 \\
\hline
\end{tabular}

\subsection{Transient Analysis}

Transient analysis is conducted numerically, and the results are presented in Figures 7, 8 and 9. It is revealed that both geometry and material played an important role in determining the structural performances. For flat head piston made of aluminum, the stress increased as increasing the time and reaching at maximum value at certain time before it is slowly decreased. Figures 8 and 9 compare the performances of two different piston head made of magnesium. It is showed that the shape piston head played a significant role where round head capable to resist the pressure and therefore reducing the stress across the connecting road. 

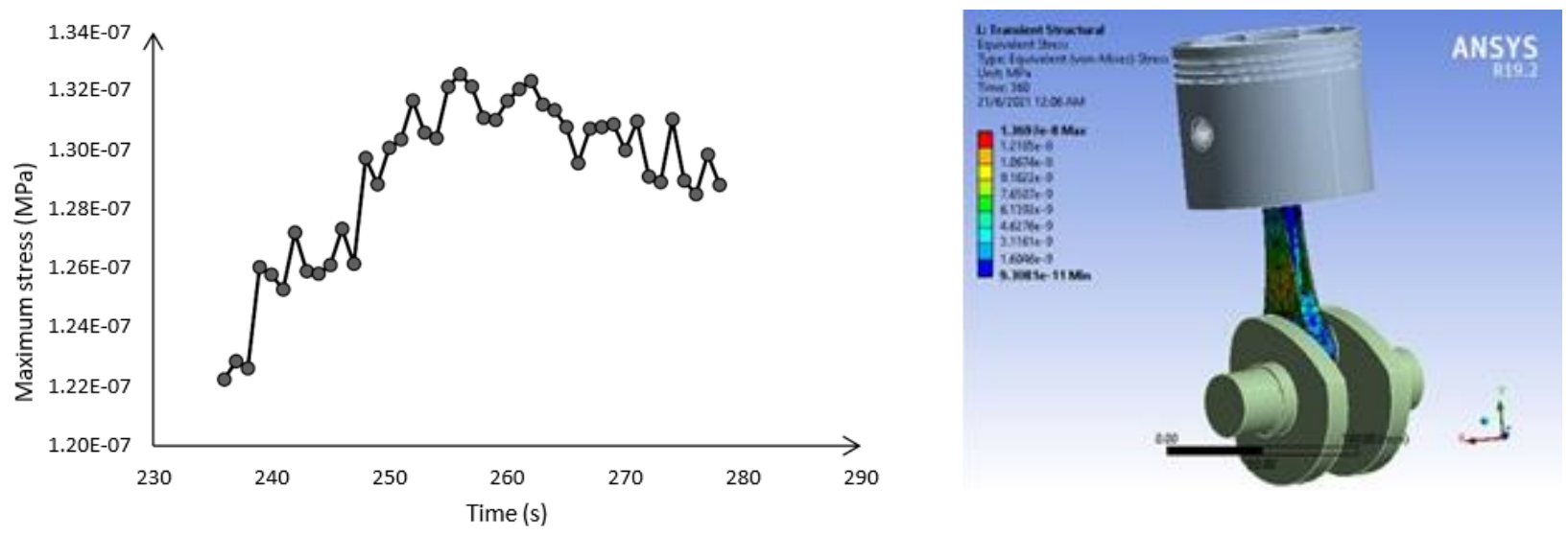

Fig. 7 - Equivalent von mises stress vs time of piston (flat head piston made of aluminum)
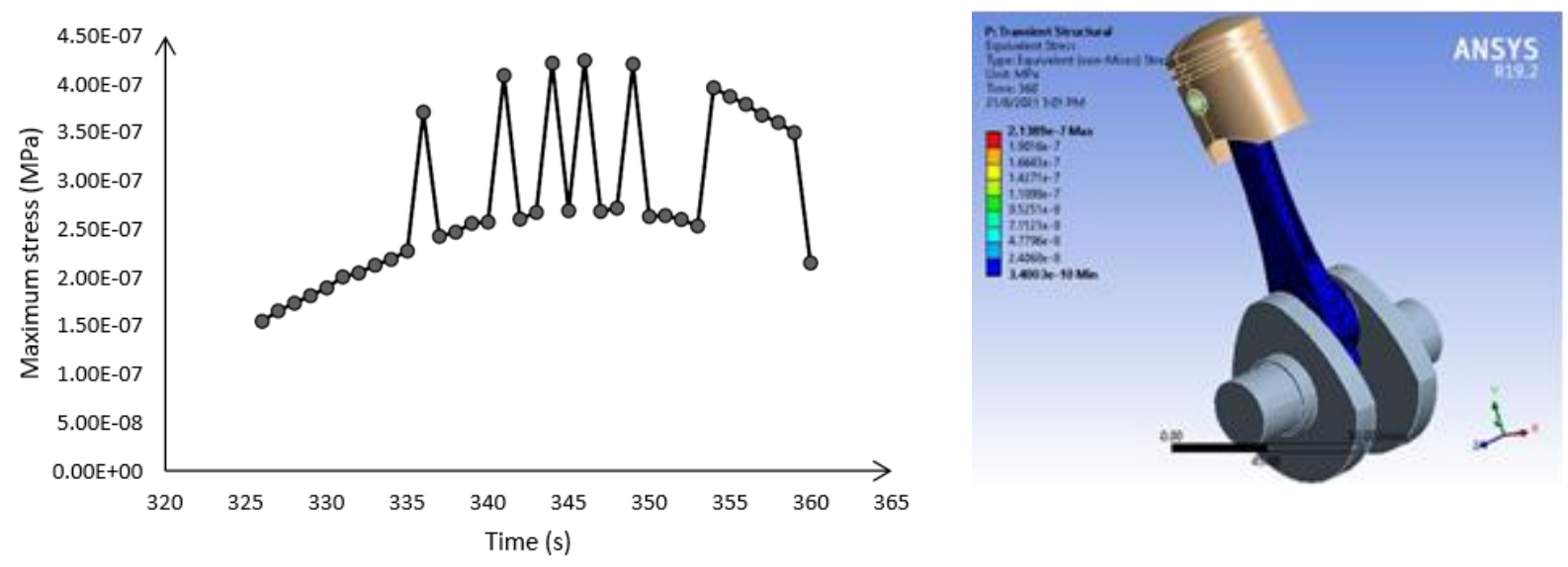

Fig. 9 - Equivalent von mises stress vs time of piston (round head piston made of magnesium)
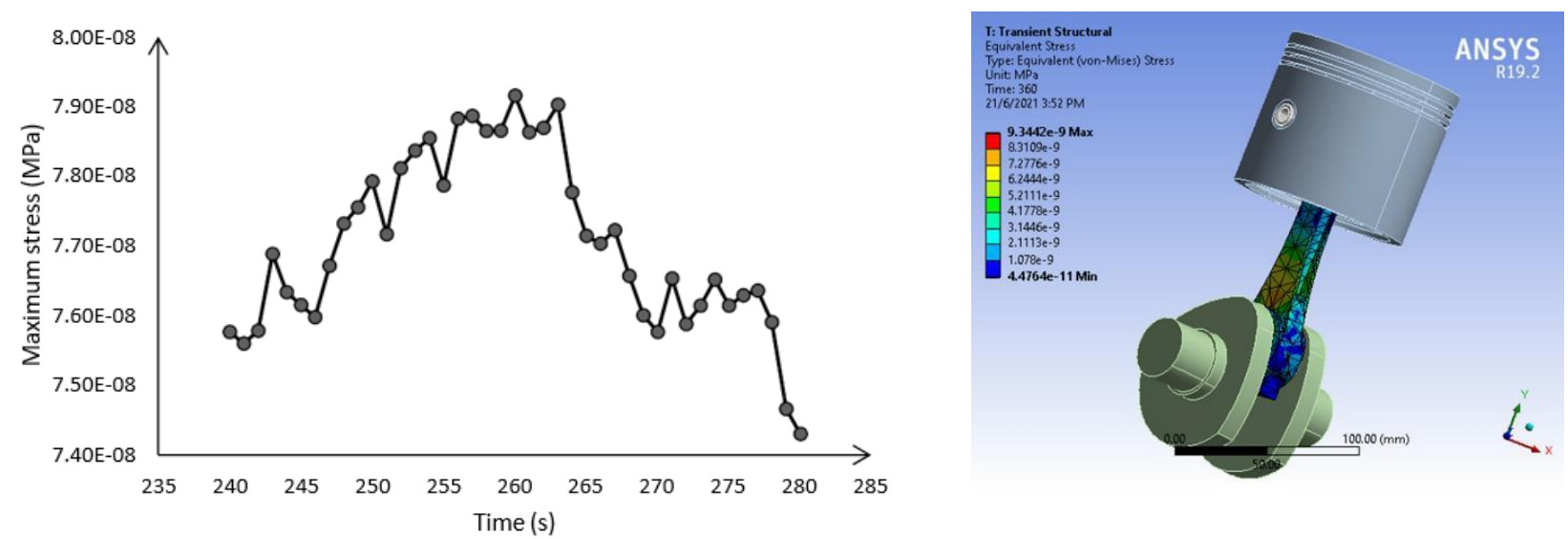

Fig. 11 - Equivalent von mises stress vs time of piston (flat head piston made of magnesium)

\section{Conclusion}

The finite element analysis using ANSYS software to vehicle piston was examined in this study, with several significant conclusions. In terms of safety, a car piston is one of the most crucial components of a vehicle. The vehicle piston material and the geometry have an important role in its car performance. This is because the piston is an internal combustion engine since it is responsible for turning the gasoline to fill up the automobile into energy drive it ahead. Using suitable material such as magnesium alloy and aluminium alloy for the piston can make the piston long lasting. Research and testing the use of different material on the vehicle piston should be thoroughly widely research in order to 
improve the automobile industry. In term of the geometry of the piston, also give some advantage for the performance of the engine. As an outcome of the analysis, it can be seen that the magnesium alloy has a low maximum equivalent stress and temperature absorb is better compared to the other material. This was achieved by comparing the mechanical response of old material with new material for the vehicle piston. The findings show that there is difference in value outcome between all of the piston samples, which are aluminium alloy and magnesium alloy, and that the geometry of piston which are round head piston and flat head piston. The magnesium alloy produces the greatest outcome. Another objective is to identify the thermal consideration for the piston samples using thermal analysis also achieved. Based on the thermal analysis results, round head piston with magnesium alloy material has the lowest result which is the best compared to another sample. However, due of the imperfection of the result sample during the analysis process, the conclusions of this study cannot be utilized as a future reference.

\section{Acknowledgement}

The authors would also like to thank the Faculty of Mechanical and Manufacturing Engineering, Universiti Tun Hussein Onn Malaysia.

\section{References}

Robinson, D., \& Palaninathan, R. (2001). Thermal analysis of piston casting using 3-D finite element method. Finite elements in analysis and design, 37(2), 85-95

Premkumar, I. I., Ganeshan, P., Sudhagar, S., Raja, K., Kumaran, S. S., \& Sekar, V. C. (2020). An investigation on Piston structural analysis related with experimental cylinder pressures using different biodiesel blend ratios. Materials Today: Proceedings, 22, 2255- 2265

Ling, B., Wei, K., Qu, Z., \& Fang, D. (2021). Design and analysis for large magnitudes of programmable Poisson's ratio in a series of lightweight cylindrical metastructures. International Journal of Mechanical Sciences, 195,106220

Liu, H., Xu, Q., Wang, Q., \& Zhang, Y. (2020, December). Prediction of the elastic modulus of concrete with spontaneous-combustion and rock coal gangue aggregates. In Structures (Vol. 28, pp. 774-785). Elsevier

Roychoudhury, A., Banerjee, A., Mishra, P. C., \& Khoshnaw, F. (2021). An FEA material strength modelling of a coated engine piston. Materials Today: Proceedings, 44, 1320-1325

Srivastav, N. K., Sahani, R. P., Kumar, A., Yadav, G., Sahani, R., Mishra, P. K., \& Pandey,

A. K. (2015). Finite Element Analysis of Piston Head by ABAQUS. International Journal of Scientific \& Engineering Research, 6(5), 24-28

Venkatachalam, G., \& Kumaravel, A. (2019). Experimental Investigations on the Failure of Diesel Engine Piston. Materials Today: Proceedings, 16, 1196-1203

Waldhauer, B., Schilling, U., Schnaibel, S., \& Szopa, J. (2004). Piston damages-Recognising and rectifying. Edition Part No-50003973-02, MSI Motor Service International GmbH, Untere Neckarstraße, D-74172 Neckarsulm

Zolekar, V., \& Wankhade, D. L. (2013). Finite Element analysis and optimization of ic engine piston using RADIOSS and OptiStruct. In altair technology conference

Gopal, G., Kumar, L. S., Reddy, K. V. B., Rao, M. U. M., \& Srinivasulu, G. (2017). Analysis of Piston, Connecting rod and Crank shaft assembly. Materials Today: Proceedings, 4(8), 7810-7819

Liu, X. F., Wang, Y., \& Liu, W. H. (2017). Finite element analysis of thermo-mechanical conditions inside the piston of a diesel engine. Applied Thermal Engineering, 119, 312-318

Robinson, D., \& Palaninathan, R. (2001). Thermal analysis of piston casting using 3-D finite element method. Finite elements in analysis and design, 37(2), 85-95

Tian, J., Wang, W., Yan, W., Jiang, Z., Shan, Y., \& Yang, K. (2016). Cracking due to Cu and Ni segregation in a 17-4 PH stainless steel piston rod. Engineering Failure Analysis, 65, 57- 64.

Deulgaonkar, V. R., Ingolikar, N., Borkar, A., Ghute, S., \& Awate, N. (2021). Failure analysis of diesel engine piston in transport utility vehicles. Engineering Failure Analysis, 120, 105008.

Jiang, Y. (2020). General mesh method: A unified numerical scheme. Computer Methods in Applied Mechanics and Engineering, 369, 113049.

Zhang, J., Xia, S., Ye, S., Xu, B., Song, W., Zhu, S., \& Xiang, J. (2018). Experimental investigation on the noise reduction of an axial piston pump using free-layer damping material treatment. Applied Acoustics, 139, 1-7.

Buyukkaya, E., \& Cerit, M. (2007). Thermal analysis of a ceramic coating diesel engine piston using 3-D finite element method. Surface and coatings technology, 202(2), 398-402.

Kourav, S. K., \& Ghagare, V. B. (2013). Design and Analysis of Piston by using Finite Element Analysis. International Journal of Engineering Research \& Technology (IJERT), ISSN, 2278-0181

Sharma, S., \& Dhakar, P. S. (2019). Thermal Analysis of Piston Using Convex and Concave Profile of Piston head International Journal of Technical Innovation in Modern Engineering \& Science (IJTIMES) Thermal Analysis of 
Piston Using Convex and Concave Profile of Piston head. June 2018. https://doi.org/10.13140/RG.2.2.16652.46727

Sonar, D. K., \& Chattopadhyay, M. (2015). Theoretical Analysis of Stress and Design of Piston Head using CATIA \& ANSYS. International Journal of Engineering Science Invention, 4(6), 52-61. www.ijesi.org

Subbarao, R., \& Vart Gupta, S. (2019). Thermal and structural analyses of an internal combustion engine piston with suitable different super alloys. Materials Today: Proceedings, 22, $2950-2956$. https://doi.org/10.1016/j.matpr.2020.03.429

Zulfattah, Z. M., Zulkifli, N. W. M., Masjuki, H. H., Harith, M. H., Syahir, A. Z., Norain, I., Jumaidin, R., Yusoff, M. N. A. M., Alwi, A., Jamshaid, M., \& Arslan, A. (2019). Effect of bio-based lubricant towards emissions and engine breakdown due to spark plug fouling in a two-stroke engine. Journal of Cleaner Production, 221(March), $215-223$. https://doi.org/10.1016/j.jclepro.2019.02.224

Vinoth, M. A., LR, A., \& Uppinal, V. K. (2014). Development and Assessment of Piston by using Al-Si Hybrid Metal Matrix Composites Reinforced with SiC and Cenosphere Particulates. Int J Eng Res Technol (IJERT), 3(7), 12341238 